\title{
David Lewis, Donald C. Williams, and the History of Metaphys- ics in the Twentieth Century
}

\author{
A. R. J. FISHER
}

ABSTRACT: The revival of analytic metaphysics in the latter half of the twentieth century is typically understood as a consequence of the critiques of logical positivism, Quine's naturalization of ontology, Kripke's Naming and Necessity, clarifications of modal notions in logic, and the theoretical exploitation of possible worlds. However, this explanation overlooks the work of metaphysicians at the height of positivism and linguisticism that affected metaphysics of the late twentieth century. Donald C. Williams is one such philosopher. In this paper I explain how Williams's fundamental ontology and philosophy of time influenced in part the early formation of David Lewis's metaphysics. Thus, Williams played an important role in the revival of analytic metaphysics.

KEYWORDS: David Lewis, Donald C. Williams, history of metaphysics

\section{Introduction}

Analytic metaphysics is alive and kicking. But it wasn't always like this. In the 1930s metaphysical speculation gradually fell out of fashion due to the growing popularity of logical positivism and the many varieties of linguisticism that were championed by ordinary language philosophers and the later Wittgenstein. This lasted until the 1960s whereupon metaphysics began to recover and eventually found itself once again in mainstream philosophy. A typical explanation for this 're-birth' of metaphysics is that the critique of logical positivism's theory of meaning and analyticity, especially by W. V. Quine in reaction to Rudolf Carnap, opened up the study of ontology and left the anti-metaphysics stance of positivism unconvincing and unmotivated. What made Quine's conception of ontology so influential was that he naturalized or domesticated metaphysics by making it part of the same continuum as science; it is not to be regarded, he thought, as a stand-alone discipline that explores a priori concepts of the pervasive features of reality, a view of metaphysics that positivists ridiculed and caricaturized. By the late 1950s ordinary language philosophers were addressing metaphysical issues in their own way. P. F. Strawson (1959) presented a 'descriptive metaphysics' by describing the general features of our conceptual structure to reveal a picture of reality that is made up of material objects and persons as 'basic particulars' in a framework of space-time. Not far behind were the semantic developments in modal logic that led to the clarification of modal notions and an increasing use of the concept of possible worlds. This was coupled with investigations into the nature of necessity and possibility as found in the work of Roderick Chisholm, Kit Fine, David Lewis, Alvin Plantinga, and others. Saul Kripke and Hilary Putnam's defense of necessary a posteriori truths and their respective theories of 'direct reference' also gave rise to a new version of essentialism. As a result, traditional questions of metaphysics were brought to the fore but were studied with modern tools of logical analysis and sophisticated views of meaning and reference. Metaphysics thus became a main part of analytic philosophy 
(for a recent history of the revival of analytic metaphysics, see Glock [2008: ch. 2]; cf. Soames [2003]).

However, metaphysics after logical positivism does not entirely owe its existence to the crumbling of the foundations of logical positivism, Quine's conception of ontology, and developments of reference and modality by Kripke, ordinary language philosophers, and others who are to be counted as taking the linguistic turn. The 1950s had flurries of metaphysical activity that were pre-Kripke, sometimes hostile to Quine, or borne out of the linguistic turn stemming from Russell and Frege in other ways. Philosophers who vaguely fit this description include Max Black, Herbert Hochberg, Anthony Quinton, J. J. C. Smart, and Richard Taylor.

We can go further back to find Hochberg's teacher, Gustav Bergmann, doing metaphysics in the 1940s, albeit in a positivistic manner due to his upbringing in the Vienna circle. Bergmann's 'ontological turn' had an impact on Hochberg in the 1950s and on some of his other students, such as Reinhardt Grossmann in the 1960s, who ought to be recognized as playing some role as an undercurrent in the revival of metaphysics. There have been recent efforts to highlight this fact (Macbride 2014). I wish to go even further back to the late 1920s and 1930s to discuss the work of the American philosopher Donald C. Williams (1899-1983) and his role in the development and revival of metaphysics in the latter half of the twentieth century. Williams defended his own brand of realism in reaction to the metaphysics of the 1900s through the 1930s and in face of the anti-metaphysical trends from the 1930s through the 1960s. Some of his views have survived as genuine options in contemporary metaphysics. His work was studied in Australia and affected the metaphysics of several Australian philosophers such as D. M. Armstrong and Keith Campbell (Armstrong 1993: 72, n. 1).

As professor of philosophy at Harvard University, Williams taught David Lewis who matriculated at Harvard University as a graduate student in the fall of 1962. Lewis attended Williams's lectures on metaphysics 'circa 1963' (Lewis 1991: 56, n. 13), did an independent study on the metaphysics of time with Williams (fall 1965 and spring 1966), and in the spring of 1965 enrolled in Williams's course 'PHIL157 Metaphysics: Problems of Cosmology'. His term paper for this course was entitled 'How to Establish the Identity Theory'; it eventually became 'An Argument for the Identity Theory' (1966). Williams was to have a lasting influence on Lewis's general metaphysical outlook and philosophy of time. After Lewis received comments from Williams on his PHIL157 term paper, he wrote a letter to Jack Smart about Williams's misgivings regarding his claim that 'the nominal essences of experiences as such are their causal roles'. Lewis says: 'I'm sorry I can't give Williams a theory he'd accept, for I've come to be quite sympathetic with almost all of what he's doing' (Letter to J. J. C. Smart, 8 May 1965, p. 2).

It should not be a surprise to learn that Lewis looked up to Williams and took on certain aspects of Williams's metaphysics although in a distinctive way, for the teacherstudent relation quite often becomes a relationship of influence and reaction (see Nolan [2007] for discussion). In addition, close readers of Lewis's work will notice the many places where Lewis cites Williams, sometimes as a tribute to Williams's work (Lewis's oeuvre contains the following explicit references to Williams: Lewis [1976: 147; 1983b: 99; 1986a: 26; 1986b: 64, 68, 93, 123; 1986c: x, 71; 1990: 30; 1991: 33, 56, 76; 1994: 474]). John Heil provides a discussion of the connection between Wil- 
liams and Lewis in his latest book The Universe As We Find It, concluding that 'the ontological picture we today associate with David Lewis can be found in fledgling form in Williams's' (2012: 110). The main thesis of this paper is that Lewis was in fact influenced in part by the Humean framework of Williams's metaphysical outlook and in part by Williams's metaphysics of time and time travel.

I italicized the phrase 'in part' to highlight the fact that I am not claiming that Williams was the sole influence on Lewis with respect to these metaphysical doctrines. Lewis also attended seminars by Quine at Harvard and by Nelson Goodman at Brandeis that influenced his general metaphysical views, metaphysics of time, and approach to ontology. Various other philosophers at various times in Lewis's career also had an impact on the development of his metaphysics. His study of Hume at Oxford in 1959 and 1960 and discussions with his undergraduate teachers at Swarthmore College-in particular, Michael Scriven and Jerome Shaffer-played a part in the formation of his views on causation and of his theory of mind. Lewis also owes much to Richard Montague at UCLA regarding counterfactuals and much to Armstrong in his adoption of a theory of natural properties.

In what follows, I compare Williams's view of the universe as a four-dimensional spread of qualities in space-time with Lewis's doctrine of Humean supervenience $(\mathbb{S} 2)$. I discuss the similarities of their views on the metaphysics of time $(\mathbb{S} 3)$ and present the debate they had in their correspondence about how a time traveler can and cannot change the past $(\mathbb{S} 4)$. I conclude with a summary and defense of my evaluation of the connection between Williams and Lewis $(\mathbb{S} 5)$.

Williams is an important but neglected philosopher. Many of his views are unheard of and the historical context in which he is situated is largely forgotten. He was raised on a diet of straight metaphysics in the mid-1920s as a student at Berkeley and Harvard, reading and becoming immersed in the work of Samuel Alexander, F. H. Bradley, Bernard Bosanquet, C. D. Broad, Edwin B. Holt, C. I. Lewis, A. O. Lovejoy, Ralph Perry, J. M. E. McTaggart, William P. Montague, Bertrand Russell, George Santayana, Roy Wood Sellars, G. F. Stout, and others. He was especially affected by the direct realism, empiricism, and materialism of Alexander (1920) and the New Realists (Holt et al., 1912), defending (Williams 1934b) and adopting direct realism about perception (Williams 1959a: 207-8; 1966b: 243-44), ${ }^{1}$ physical reductionism about color and other secondary qualities (Williams 1930: 520; 1944: 433; 1966b: 228-29), and metaphysical materialism, the view that 'every existent entity is located, extended, and composed in space and time' (Williams 1946: 580).

In the 1950s Williams devoted much of his efforts to what he called 'analytic ontology'. In 'On the Elements of Being' (1953a, 1953b), Williams articulated a fundamental ontology of abstract particulars or 'tropes', although he had argued for the existence of abstract particulars as early as 1931 (see Williams 1931: 589). ${ }^{2}$ According to Williams, tropes constitute the one and only fundamental category of being. Concrete particulars and abstract universals are reduced to or analyzed in terms of abstract par-

\footnotetext{
${ }^{1}$ Throughout I cite the original articles by Williams and provide the corresponding reference from his collection of papers: Principles of Empirical Realism (1966b) if the work I'm citing is reprinted in the collection, and I include a page reference.

${ }^{2}$ For recent work on trope ontology, see (Maurin 2002; Schneider 2002; Trettin 2000). For a classic book on tropes in contemporary metaphysics, see (Campbell 1990).
} 
ticulars. Concrete particulars like tables and chairs are mereological sums of compresent tropes and abstract universals like Redness and Justice (on the 1953 view) are sets of similar tropes. What is often overlooked is that by $1957^{3}$ Williams had given up on this set-theoretic view of universals and endorsed a variety of immanent realism according to which tropes 'manifest' universals (Williams 1959[1986]: 7-10; 1963: 61517). He also defended the view that the past, present, and future are equally real and the view that concrete particulars are composed of temporal parts (Williams 1951a, $1951 \mathrm{~b})$. He continued to write on the metaphysics of time and time travel in the 1960s and presented an updated version of his metaphysical system in his 1974 University of Notre Dame lectures: 'The Elements and Patterns of Being' (DCW Papers, HUG(FP) 53.45, box 8, folders marked: 'Notre Dame Lectures 1974', HUA).

Williams grew up on the edge of an era in the early twentieth century during which metaphysics was all the rage but at a tipping point and about to decline. It is true that in the 1930s many philosophers still did metaphysics. Broad's Examination of McTaggart's Philosophy is a case in point. But most of these philosophers were of a previous generation. Williams was still quite young and would only reach his peak in the 1940s and 1950s. Moreover, unlike other philosophers of his generation (born between 1890 and 1910), he was not raised on positivism like Bergmann and Black, nor did he follow the tide of linguisticism when it began to flourish. He stuck with the concerns of the figures of earlier generations who believed that metaphysics was a legitimate enterprise. Williams defended metaphysics as a form of inquiry that consisted of genuine knowledge of the nature of things and argued vehemently against positivism (Williams 1937/1938, 1938) and linguisticism (see, for instance, Williams 1959b). His philosophical method was based on induction (Williams 1947) and the weighing up of competing hypotheses against the scientific picture of the world, common sense, and a theory's explanatory power and simplicity. He argued for all of his views on these grounds (see, for instance, Williams 1934a). He can be seen as an early defender of 'inference to the best explanation', a common justification for hypotheses in contemporary metaphysics. Williams thus occupies an important part in the history of philosophy and can be seen as a vital 'link' connecting the metaphysics of the early and later parts of the twentieth century.

\section{Williams's Actualism and Lewis’s Humean Supervenience}

Williams defended a basic metaphysical view he called actualism. He writes,

[A]ctualism is [the view] that the world is composed wholly of actual or factual entities, including concreta like a horse and abstracta like his neigh, and the sums and the sets thereof, all on the one plane of particular and definite existents. There are no substrata of potency or prime matter, no forces or virtues, no blur of indefiniteness or press of tendency; no superstructure of unexampled essences or disembodied possibilities or transcendental acts of being. (Williams 1959a: 203; 1966b: 239)

\footnotetext{
${ }^{3}$ On 22 November 1957 he wrote to Richard B. Brandt in reply to Brandt sending an offprint of Brandt's 1957 article. In this letter Williams proposes his revised theory of universals (Donald Cary Williams Papers, HUG(FP) 53.6, box 8, folder 2, Harvard University Archives). The first and last parts of all future references to the Williams Papers will be abbreviated to 'DCW Papers' and 'HUA' respectively.
} 
As with other varieties of actualism that appeared after Williams's view, there are no concrete possible worlds, concrete possible individuals, possibly existing things, or nonexistent objects. His actualism is notably austere in its rejection of causal powers, primitive dispositions, and necessarily existing abstracta such as states of affairs or propositions, things later actualists are happy to posit (Adams 1974: 231, n. 8). Williams's actualism is not only a statement about what exists. It is also a fundamental ontology. The passage quoted above continues,

Our actual entities, I specify further, are all either simple [qualities], or relations belonging to one of three primitive categories, or some compound of these. The relational categories which I think sufficient and necessary are the whole-part or "merological" relations, resemblances or "comparisons," and locative distances and directions, not necessarily the physical geometry of space-time, but at least some analogous modes of deployment. (Williams 1959a: 203-4; 1966b: 239-40; cf. Williams 1959[1986]: 2-4)

According to Williams, there are only actual qualities and these are governed by three fundamental relations: (1) spatiotemporal relations, (2) parthood relations, and (3) similarity relations. There are no other fundamental relations, and any other relations that exist are merely compounds or combinations of these three relations. Our world, then, is a system of space-time littered with simple qualities in various arrangements throughout a four-dimensional manifold, along with mereological sums and sets of these quality distributions. The qualities that are spread over space-time stand in internal similarity relations to each other of a wide degree and variety. This white quality and that white quality exactly resemble each other, whereas this crimson quality somewhat resembles that vermillion quality, and more so than our initial white qualities, and so on.

Facts of similarity provide explanatory power in certain ways. For Williams, they account for ways things could have been. The relevant set or sum of actual qualities resembles the set or sum of qualities that could have been instantiated or could have occurred at the same place and same time. The actual world as a field of similarity constitutes many 'attribute spaces' that resemble the actual world and other 'attribute spaces' in infinite ways (Williams 1959[1986]: 14; see also Williams 1963).

Regarding the parthood relation, Williams accepts classical extensional mereology. He thinks there are gerrymandered sums composed of Napoleon, the moon, and that elm tree as well as concrete objects found in everyday experience such as tables and chairs. He also thinks there are mereological sums of qualities that are either scattered across space-time or in the same region of space at the same time. Williams's motivation for the thesis that any two things compose an object is based on vagueness. $\mathrm{He}$ writes,

We have in daily life a job lot of useful tacit rules about what extra patterning of position and resemblance, on top of the bare partitive relations, suffices to distinguish "real things" or "wholes," like an atom, an axe, a cabbage, a man, from "mere sums": the former are solid, they contrast with the milieu, they hang together while they move, and so forth. But the idea is vague. (Williams 1959a: 219; 1966b: 255)

Williams's argument is that the notion of an 'intuited integrity' that we assign to objects such as ourselves or ordinary objects is vague and therefore does not provide grounds for positing an additional relation to the three we have already admitted. He thus anticipates more refined arguments against restricted composition that are still 
discussed (see, for instance, Miller 2005) and that stem from Lewis's vagueness argument (Lewis 1986b: 212).

According to Williams's preferred theory of properties, qualities are tropes or abstract particulars. But his actualism does not depend on this thesis. In his 1974 lectures at the University of Notre Dame he begins with the more theory-neutral notion of 'particular entity' or 'actual element' and explains at length how 'elements' stand in spatiotemporal and mereological relations (Lecture 1, pages marked '102-110'; DCW Papers, HUG(FP) 53.45, box 8, folder: "How Reality is Reasonable' Notre Dame Lectures 1974', HUA). He is thus bracketing what the nature of the relata of these two fundamental relations really are. Furthermore, it is only when he considers the resemblance relation that he introduces the notion of a quality and in a similar way he leaves it open whether qualities are tropes, universals, or something else entirely.

Williams speaks of qualities as primitive entities and space and time as mere relations. So he seems to be committed to the relational theory of space and time. But at the current level of abstraction Williams is not committing himself to any particular theory of space and time, beyond saying that time is just another dimension of the extensive manifold. He thinks specific questions about the nature of space and time fall under the inquiry he calls 'speculative cosmology', which is to be contrasted with the more general and prior mode of inquiry he calls 'analytic ontology'. In constructing his fundamental ontology of qualities and relations, he is open to physical science telling us that space and time are mere relations between primitive entities or that space-time is a substance-like thing or stuff in which objects with qualities are located or that space-time is made up of points that directly instantiate simple qualities.

For Williams, at the fundamental level we have arrangements of qualities in a fourdimensional manifold that stand in parthood and resemblance relations to each other in myriad ways. There are no other relations or necessary connections between distinct entities. Williams's actualism is therefore incompatible with causal relations that fail to supervene on the four-dimensional arrangements of qualities. He writes,

[Actualism] seems also inhospitable toward anything like an entailment between cause and effect, for the same traits of it which enable one fact about one locus to entail another fact about the same locus, as This is square entails This is rectangular, and enables one locus to be similar or dissimilar to another, preclude that a fact about one locus should entail a fact about another locus. There surely can be no transeunt entailments in a manifold of existence and location. (1953c: 122, his italics)

Williams objects to theories of causation according to which 'causal connection is, in a sense, a necessary connection' (Ushenko 1953: 92). According to A. P. Ushenko, if there is a causal chain connecting $A, B$, and $C$ in this order, then it is impossible that ' $a$ state different from $B$ might have occurred between $A$ and $C$ ' (Ushenko 1953: 99). Williams thinks it is metaphysically possible for two events that are causally related not to be so related. The manifold fails to entail any (qualified or unqualified) necessary connections that could be labeled the 'causal relation' qua entailment between two events. To illustrate, take the events, $A, B, C$, and $F$ and suppose that $B$ occurs between $A$ and $C$. Williams thinks that,

$F$ instead of $B$ might have occurred between $A$ and $C$, [and when we say this] we mean that the nature of $A$ and the nature of $C$ and the fact that there is something between them (with all the rest of the universe thrown in, if you like) no more entail that the 
something is $B$ than it is $F$, and quite conceivably they might not even make the one any more probable than the other. (1953c: $125, \mathrm{n} .2)$

The manifold and how its parts are related are contingent and thus independent of each other. There are no necessary connections between distinct existents of the manifold, nor do they realize irreducible causal powers. For, as Williams says, '... it does not matter how thick or how thin we slice the world bologna-every slice remains logically independent of every other' (1953c: 124-25, n. 2); '[c]ausation is at most regular sequence, but also it is at least regular sequence' (Williams 1953c: 121).

Admittedly, for this argument to work we need to accept Williams's actualism. Ushenko would probably reject it given his view of causation. So there appears to be some question-begging going on in this debate. However, Williams interprets the issue to be about what view of causation follows from our best metaphysics. Williams thinks his actualism is more likely to be true because 'it is a scheme of analysis and construction on a deeper level, and better certified, than any particular hypothesis, so close under the wing of logic and so integral to science that only the sharpest criticism and most monumental counter-construction could turn the scale in favor of a fundamentally opposed philosophy' (Williams 1953c: 122). Thus, Williams's argument is that since his actualism is most likely true and Ushenko's view of causation is incompatible with it, Ushenko's view of causation must be rejected.

Williams's actualism and his denial of necessary connections between mereologically distinct entities bear a striking similarity to Lewis's starting point in metaphysics:

Humean supervenience is named in honor of the greater denier of necessary connections. It is the doctrine that all there is to the world is a vast mosaic of local matters of fact, just one little thing after another. (But it is no part of the thesis that these local matters are mental.) We have geometry: a system of external relations of spatiotemporal distance between points. Maybe points of spacetime itself, maybe point-sized bits of matter or aether or fields or both. And at those points we have local qualities: perfectly natural intrinsic properties which need nothing bigger than a point at which to be instantiated. For short: we have an arrangement of qualities. And that is all. There is no difference without difference in the arrangement of qualities. All else supervenes on that. (Lewis 1986c: ix-x)

For Lewis, there is nothing more to the actual world than a multitude of particulars with qualities or properties spread out in space-time. Each particular stands in a spatiotemporal relation to every other particular; hence they form a system of 'relations of spatiotemporal distance'. Each particular can be recombined in various ways to yield different arrangements of qualities. If $A$ and $B$ contingently exist and are mereologically distinct, there are no necessary connections between $A$ and $B$. They can be recombined in various ways by standing in differing spatiotemporal and mereological relations, and they can exist apart in distinct worlds (or at least their counterparts can).

Humean supervenience provides the framework for a theory of causation and the laws of nature. On a rough Humean picture, causal relations are not necessary connections between events or existents. Similarly, laws of nature can be taken as mere regularities. However, on Lewis's view, things are a bit more complicated. Lewis adopted a counterfactual theory of causation (as early as 1960 during his undergraduate visit at Oxford) and the best-systems view of lawhood, which was inspired by F. P. Ramsey 
(Lewis 1973: 73-74). This is one respect in which Lewis articulates the Humean picture independent of Williams's actualism.

The Humean denial entails the rejection, according to Lewis, of theories of the laws of nature that admit necessary connections. To illustrate, Armstrong defends the view that laws are to be understood as relations among universals. More precisely, he thinks that if the lawmaking relation, call it $N$, holds between universals, say, being $F$ and being $G$, and being $F$ occurs, then being $G$ must of necessity occur. To be clear, lawmaking relations like $N$ hold contingently between universals. But when they do hold, they hold necessarily (see Armstrong 1983). It is this necessary connection that Lewis objects to (Lewis 1983a: 365-66; 1986b: xii). Lewis's Humean denial of necessary connections does not stop there. It grounds his rejection of states of affairs (Lewis 1998), structural universals (Lewis 1986a), truthmaking (Lewis 2001: 611-12), magical ersatzism (Lewis 1986b: 179-82), and Armstrong's combinatorial theory of possibility (Lewis 1992). The Humean principle of insisting that entities must be modally free of each other is at the center of Lewis's metaphysics.

The similarity in doctrine between Williams's actualism and Lewis's Humean supervenience is no accident. Lewis was influenced by Williams's actualism. This was the metaphysical view that he was instructed to master. Lewis was exposed to this Humean-inspired metaphysical picture in several courses at Harvard. Given Lewis's Humean inclinations, which most likely came from his time at Oxford as a visiting student, he naturally absorbed Williams's insights into his own metaphysics. Lewis acknowledges his intellectual debt to Williams in a letter to T. L. S. Sprigge in which Lewis is discussing Aristotle. Lewis confesses that he has 'little knowledge of the ancients' but goes on to mention that: 'I owe a great deal to my study of metaphysics with D. C. Williams, and I wish it had been with him rather than with certain of his colleagues that I had tried to study the ancients' (Letter to T. L. S. Sprigge, 25 February 1994). This admission by Lewis also shows us how much Lewis looked up to Williams as a teacher of metaphysics and of topics in the history of philosophy. Let us now consider the connection between Williams's and Lewis's views on the metaphysics of time.

\section{Four-Dimensionalism and Time}

In his writings on time Williams defends what he calls the theory of the manifold or simply the (pure) manifold theory. According to the manifold theory, 'the universe consists, without residue, of the spread of events in space-time, . . . the fourdimensional fabric of juxtaposed actualities' (Williams 1951a: 458; 1966b: 290). Things are spread out in time just as much as they are spread out in space. They are four-dimensional solids. And '[since things] are four-dimensional solids, we may and often must distinguish temporal parts as well as spatial ones. We acknowledge, for example, the October 1959 span of, say, a horse's total being as well as the horse's neck for his life long' (Williams 1959[1986]: 3). That is, objects are composed of temporal parts and persist by having different temporal parts at different times. Call this view four-dimensionalism. Since objects or events are spread out in time as they are in space, it seems reasonable to think, says Williams, that the past, present, and future exist simpliciter. To be sure, '[f]uture events and past events are by no means present events, but in a clear and important sense they do exist, now and forever, as rounded 
and definite articles of the world's furniture' (Williams 1951b: 282; 1966b: 262). Call this view eternalism. Sometimes the manifold theory is subsumed under actualism since, according to Williams's view, the world is a four-dimensional manifold of actual entities. At other times he identifies the manifold theory with actualism. Nothing hangs on this difference for present purposes.

Like Williams, Lewis adopts four-dimensionalism and eternalism. There is a close similarity in their characterization of some of these doctrines. For instance, Williams says ' $[t]$ he world may be either a hodgepodge or some single sinuous time streams-or, perhaps we should say, time "streaks" (1966a: 32); in almost identical fashion Lewis says '[e]nduring things are timelike streaks' (1976: 145). A similarity in wording also occurs when they state their preferred account of change. Here is Williams:

[Change is] qualitative alternation of a thing, for example, the turning of a leaf from green to red, [which] consists of a four-dimensional worm's having different qualities in different temporal parts, as a leaf may also be green in one spatial half and red in the other. (1966a: 11)

Here is Lewis on change:

Change is qualitative difference between different stages—different temporal parts—of some enduring thing, just as a "change" in scenery from east to west is a qualitative difference between the eastern and western spatial parts of the landscape. (1976: 14546)

Also compare Lewis's passage with this quotation from Williams:

Time "flows" only in the sense in which a line flows or a landscape "recedes into the west." That is, it is an ordered extension. And each of us proceeds through time only as a fence proceeds across a farm: that is, parts of our being, and the fence's, occupy successive instants and points, respectively. (Williams 1951a: 463; 1966b: 295)

There is also a similarity in what they had to say about the possibility of time travel. In this case there is clear evidence from their correspondence that suggests Lewis was familiar with Williams's work on the subject. Williams and Lewis also had detailed discussions in conversations when the Lewises visited the Williamses. Williams's fascination with the metaphysics of time occupied a large chunk of his academic efforts throughout the 1960s while he was at Harvard and in California. There are only scant remarks about time travel in his published works on time from the 1950s, but his unpublished work includes several papers on the subject (DCW Papers, HUG(FP) 53.45, box 4, HUA). He presented 'The Metaphysical Mechanics of Time Travel' on 6 April 1960, 'Principles and Practices of Time Travel' on 8 March 1962 at Haverford College, 'The Nature of Time' read in June 1966 (this unpublished paper was on the reading list of Lewis's famous 'PHIL318' class at Princeton from 1985 onwards), 'The Shape of Time' in Claremont, CA, February 1968, and 'Critique of Logical and Theological Fatalism’ on 24 January 1969 at UCLA (which Lewis attended ${ }^{4}$ ).

Now, time travel in the sense that someone travels back in time or travels far into the future is said to be contradictory and therefore metaphysically impossible because one cannot be at a later time living at an earlier time. It is incoherent to say, so the ob-

\footnotetext{
${ }^{4}$ Williams wrote a letter to David and Stephanie Lewis dated 31 January 1969 in which Williams runs through comments that Lewis made at the talk (DCW Papers, HUG(FP) 53.6, box 9, folder 1, HUA).
} 
jection goes, that in five minutes from now I will be walking through the Pleistocene, which existed at a time before now. Call this the dual temporal antinomy (for one proponent of this objection, see Taylor (1963[1992]: 73)). In 'The Myth of Passage' it appears Williams affirms the dual temporal antinomy and is therefore committed to saying that time travel is contradictory. For he thinks time travel is to be analyzed as,

the banality that at each different moment we occupy a different moment from the one we occupied before, or the contradiction that at each different moment we occupy a different moment from the one which we are then occupying-that five minutes from now, for example, I may be a hundred years from now. (1951a: 463; 1966b: 296)

But this is not his view, or at least he changed it by 1956. In the reprint of 'The Myth of Passage' he added that time travel is 'conceivable after all' and that according to the manifold theory 'it would consist of a man's life-pattern, and the pattern of any appliances he employed, running at an abnormal rate or on an abnormal heading across the manifold' (Williams 1956: 327; 1966b: 303).

In 'The Nature of Time' Williams argues that on the manifold theory all travel through time is nothing more than 'the gross shape and the finer internal configuration of space-time worms or world lines' (1966a: 35). If Williams, say, travels back in time to the year 1766 to meet Molly Stark, then his personal time streak is at odds with the 'regular main time stream' in which ordinary individuals persist (Williams 1966a: 35). He continues, '[i]nternally our venturesome 'worm' must embody only twenty minutes' worth of occurrences in the stretch which extends through two hundred years of the main time stream' (1966a: 35-36). Williams solves the dual temporal antinomy, then, by drawing a distinction between internal processes of the time traveler and the main stream of four-dimensional reality. The twenty minute journey two hundred years into the past is spread out more thinly in the manifold whereby the internal processes of a time traveler, which seem to the traveler to be occurring at a normal rate, are actually taking much longer according to the main time stream.

In July 1971 Lewis gave the Gavin David Young Lectures at the University of Adelaide on 'The Paradoxes of Time Travel'. In the paper that came to bear the same name as the lectures and was eventually published in $1976,{ }^{5}$ Lewis argues that time travel is possible and attempts to solve a number of paradoxes that entail the impossibility of time travel. The ancestor of this paper was: 'Could a Time Traveler Change the Past?', first written about September 1970. In both versions Lewis addresses the dual temporal antinomy. Like Williams, Lewis introduces a distinction between personal and external time to solve this antinomy. The important development is that personal time is given a functional definition. Personal time for the time traveler is whatever occupies the role 'in the pattern of events that comprise the time traveler's life' (Lewis 1976: 146). Suppose it takes one hour for Williams (in his personal time) to travel back in external time to meet Molly Stark in 1766. Thus, in Lewis's view, if we utter in 1966 'Williams will be in the past', what we mean is that 'a stage of him is slightly later in his personal time, but much earlier in external time, than the stage of him that is present as we say the sentence' (Lewis 1976: 146).

\footnotetext{
${ }^{5}$ Lewis intended to publish the lectures in a revised form as a 'semi-popular' book. But he realized in 1975 that the project was beginning to be swamped with other work he had on his plate. So in 1976 he published the original paper with revisions based on his 1971 lectures (Letter to Hugh Mellor from David Lewis, 2 December 1977).
} 
Thus far, the difference between the conceptual apparatus of Williams's and Lewis's solution of the dual temporal antinomy is more or less minimal. But there are differences in what they think time travel amounts to. Following Putnam (1962: 666), Williams thinks the temporal parts of a time traveler must be spatiotemporally continuous. The abnormal stages of a time traveler into the past that 'run backward' under reversed entropy must be spatiotemporally continuous. A time traveler cannot be composed of spatiotemporally disconnected person-stages. One motivation for this restriction is that the idea of 'traveling' into the past or into the future involves some kind of 'journey' in the manifold. This journey will naturally consist of spatiotemporally continuous temporal parts. Thus, time travelers must have spatiotemporally continuous temporal parts.

Lewis is more liberal in his understanding of time travel. It just is 'a discrepancy between time and time' (Lewis 1976: 145-46). He accepts the Putnam-like case as an instance of time travel but is open to cases where a time traveler has spatiotemporally disconnected person-stages (so long as there is causal dependence between the time traveler's person-stages). If time travelers can pop in and out of existence at scattered space-time regions of the manifold, then their temporal parts need not be spatiotemporally continuous. Let us move on to their disagreement about the sense in which time travelers can and cannot change the past.

\section{Changing the Past and the Williams-Lewis Correspondence}

Consider Tim the time traveler who in 1971 travels back in time to kill Grandfather in 1921. If Tim goes back to 1921 and is ready and willing to shoot Grandfather, it seems he can do so. Tim has the ability, just like an ordinary person, say, Tom to kill Grandfather. But, it seems Tim cannot kill Grandfather. The year 1921 in which Grandfather existed is identical with the year 1921 to which Tim traveled back, and the momentary events that make up 1921 have already occurred with Grandfather surviving timelessly (although not fatalistically). Tim cannot change the past from what it was originally, nor can anyone 'change a present or future event from what it was originally to what it is after you change it' (Lewis 1976: 150). The fact that momentary events lack temporal parts entails that they are not subject to change. Of course, this is not to deny that you can change the present or future by changing the unactualized way they, that is, the present or future, 'would have been without some action of yours to the way they actually are' (Lewis 1976: 150). Therefore, although Tim doesn't kill Grandfather, he can 'because he has what it takes' and he cannot 'because it's logically impossible to change the past' (Lewis 1976: 150). Thus, a time traveler can and cannot change the past-a contradiction. Call this the changing the past antinomy.

Williams thinks someone can affect the past 'in as much as any events which actually exist in the past may turn out to have been caused by things which a time traveler carried back from a later date' (Williams 1966a: 38). But, he thinks,

it is a contradiction that a person may 'affect the past' in the sense that he changes the past, as if the year 1766 could happen once without interference from time travel and then happen over again with interference, that is, as if by some technical jiggerypokery 
I could bring it about that something which actually happened didn't happen, or that something which never in fact happened did happen. (1966a: 38, his italics)

Indeed, for Williams, we have knowledge about certain facts of the manifold, namely, facts about what has occurred in the recent past. The manifold theory, as Lewis also thinks, timelessly includes the past events that it has. So, whatever impact time travelers may have enacted on the past has already been made. Williams writes,

The only answer to that favorite query of the science fictioneer, what would happen if a time traveler went back and strangled his own grandfather, is, not that he couldn't do it, but simply that, since he himself exists, it is plain that he didn't do it, and therefore that he won't do it. (1966a: 39, his italics)

Williams further thinks that if an agent does not perform an action at a particular time or at a particular location of the space-time manifold, then that agent cannot perform that action at that particular time or particular location of the space-time manifold. To use Williams's example, '[t]he man who 'can' but doesn't run a mile in four minutes, jolly well can't run a mile in those four minutes' (Letter to David Lewis, 13 April 1971, p. 2, his italics; DCW Papers, HUG(FP) 53.6, box 9, folder 3, HUA). So Tim could have killed Grandfather in 1921, but because he didn't do it in 1921, it follows that he can't in 1921.

Lewis's solution is that the word 'can' shifts meaning given differing contexts that are fixed by differing sets of facts we consider with respect to whether or not Tim can kill Grandfather. Tim 'can' kill Grandfather relative to sets of facts that do not include the fact that Grandfather survived 1921. Tim 'cannot' kill Grandfather relative to sets of facts that do include the fact that Grandfather survived 1921 (Lewis 1976: 151). This contextualist account of 'can' explains how Tim can (in one sense) and cannot (in another) kill Grandfather. Lewis sent the ancestor of (Lewis 1976) to Williams sometime between December 1970 and April 1971. Having read Lewis's paper Williams objects to Lewis's contextualist account as follows:

There does seem to be such a lax and relational use of "can" as you describe but I can't believe it is as all-fired lax as you stipulate; it doesn't permit us to say that $x$ 'can' do $a$ if we can cite the presence of just some favorable conditions for doing $a$; they must be of a sort which we have reason to believe to be crucial and sufficient in the prevailing situation on a stipulated occasion. (Letter to David Lewis, $13 \& 28$ April 1971, p. 2, his italics; DCW Papers, HUG(FP) 53.6, box 9, folder 3, HUA)

Williams's idea is that we are not entitled to bracket the fact that Grandfather survived when evaluating whether or not Tim is able to kill Grandfather. Grandfather's survival is crucial to the situation as stipulated in the case of Tim's traveling back to the past. Moreover, we know (and so does Tim) that Tim didn't kill Grandfather as stipulated in the situation. We must include this fact in the set of facts relative to whether Tim can or cannot kill Grandfather. Williams concludes that it is:

more accurate to describe Tim's situation by saying that although in relation to his preparations to kill his grandpa, which in the usual sorts of circumstances are usually effective, so that ceteris paribus it would be highly probable not just that he can but that he will succeed, there are other data, specifically the observations that convince us, and him, that grandpa flourished until a much later date, which make it virtually certain that he does not polish off that personage. (Letter to David Lewis, 13 \& 28 April 1971, pp. 2-3; DCW Papers, HUG(FP) 53.6, box 9, folder 3, HUA) 
In reply Lewis says: 'You say "the man who 'can' but doesn't run a mile in four minutes jolly well can't run a mile in those four minutes"; and in general, failure to do something is decisive reason to conclude that ability was lacking' (Letter to Donald Williams, 12 May 1971, p. 3, his italics; DCW Papers, HUG(FP) 53.6, box 9, folder 3, HUA). However, Lewis argues, our ordinary concept of what it is to be able to do something is not captured by the fact that if person $x$ fails to do $a$ it is because $x$ lacks the ability to do a. Lewis fails to type on his typewriter while sleeping, but surely it does not follow that Lewis lacks the ability to type. He continues,

I would suppose that Tim's failure is explicable; and explicable not just by appeal to the fact that Grandfather lived on, but explicable in some commonplace way, just like Tom's parallel failure. But I would not infer from this that Tim lacked the ability to succeed. Similarly, if I hit the wrong key, I presume my failure to type correctly is explicable, but I don't think it follows that whatever prevented me from typing correctly did so by momentarily depriving me of my ability to type. (Letter to Donald Williams, 12 May 1971, p. 3; DCW Papers, HUG(FP) 53.6, box 9, folder 3, HUA)

Lewis wants an explanation of Tim's ability to kill Grandfather to be equally applicable to persons who aren't time travelers. He has two reasons for this. One is metaphysical, and the other is methodological. The metaphysical reason is that Tim and Tom's failure to change the past is due to the fact that momentary events in virtue of lacking temporal parts cannot be changed. Hence, none of us, regardless of how we travel through time, can change the past in the same way. The methodological reason is that, according to Lewis, our common concept of 'what it takes for someone to be able to do something' should apply to all persons. The latter reason stems from Lewis's project of providing conceptual analyses of the content of ordinary thought and language.

Williams objects in his final letter that appealing to the fact that momentary events lack temporal parts and because of this cannot be changed is irrelevant to Tim's specific failure. Williams writes,

[Tim] is just as unable to change those events in grandpa's life which do have temporal parts as to change those (instantaneous) ones which don't have temporal parts. Your central contribution is that there is a sense in which Tim can kill grandpa and a sense in which he 'can't'; it does seem relevant that change, including killings, requires temporal parts; and yet I can't see how it is relevant to either Tim's ability or his inability. (Letter to David Lewis, 8 June 1971, p. 2, his italics; DCW Papers, HUG (FP) 53.6, box 9 , folder 3 , HUA)

It is irrelevant, Williams thinks, to say that Tim cannot kill Grandfather in virtue of the fact that momentary events lack temporal parts. All that is needed is the claim that the year 1921 that Tim travels to is identical with the original year 1921 and not an assumption involving the four-dimensionalist account of change. The fact that Tim cannot change the past is better explained, according to Williams, by the fact that either Tim did or didn't kill Grandfather in conjunction with the fact that the events pertaining to Grandfather are timelessly embedded in the four-dimensional manifold (although he thinks this does not entail fatalism). It is wrong-headed, Williams thinks, to reduce Tim's inability to Tom's inability because this undermines what is metaphysically strange about Tim. 
Whatever we are to make of their dispute, it is obvious that much of Lewis's interest in the topic comes from his familiarity with Williams's work on the metaphysics of time. We can infer this from the fact that they discussed fatalism and other issues in the metaphysics of time in person and in correspondence. Why else would Lewis send a typescript copy of his paper to Williams? Lewis was sympathetic to Williams's general metaphysical view and developed his own account of time travel within the spirit of Williams's Humean-cum-four-dimensionalist metaphysic. Their main dispute regarding time travel is relegated to in-house details about how to properly explain antinomies of time travel.

\section{Conclusion}

I have argued that Williams was an important influence on Lewis's Humean metaphysics and philosophy of time. You might object that the manifold theory, fourdimensionalism, and eternalism were present in the work of Quine and Goodman, and given that Lewis embraced extensionalism and Quine's criterion of ontological commitment, Lewis is indebted to Quine and Goodman regarding these metaphysical ideas and not Williams. It seems, the objection concludes, that Lewis was quite distant from Williams, and so Williams was not a major influence on Lewis.

In reply, I reiterate my main thesis: Lewis was influenced in part by Williams. I do not contend that Williams was the sole influence on Lewis or that Lewis got all his metaphysics from Williams. Lewis was influenced by Quine and Goodman with respect to four-dimensionalism, but it does not follow that Quine and Goodman were the only influences on Lewis in this respect. It is clearly possible that Williams was also an influence on Lewis. Indeed, Williams was probably more of an influence here. In Word and Object Quine gives very short remarks about objects being composed of temporal parts (Quine 1960: 171) and does not even mention the four-dimensionalist account of change. Quine is mostly concerned with the reducibility of tense statements to tense-less statements in a 'canonical notation'. By contrast, Williams is not concerned with constructing a canonical notation that is meant to be indistinguishable from, as Quine puts it, 'a limning of the most general traits of reality' (1960: 161). Williams thinks we can theorize (within the framework of 'inference to the best explanation') about the nature of entities without having to theorize about language first. Lewis seems to fall more on the side of Williams here than that of Quine.

Moreover, I doubt that Lewis inherited his Humean metaphysic mostly from Quine or Goodman. The Humean mosaic is most vivid in Williams's fundamental ontology and something that Lewis would have naturally picked up on from Williams given Lewis's Humean inclinations. It is true that Quine's criterion of ontological commitment, Goodman's Structure of Appearance, and their nominalism were important in the formation of Lewis's conception of ontology and his theory of properties. My main thesis does not conflict with this fact. Also, recall that Williams's actualism, like Lewis's Humean supervenience, is explicitly neutral toward specific theories of properties.

In Lewis's 1991 acceptance speech for the Behrman Award he tells us in a biographical tone of his intellectual debts: 
I suppose my historical ancestors are, above all, Leibniz and Hume (unless certain revisionists are right about Hume's teachings, in which case my real ancestors are the inventors of a fictitious Hume). And more recently Mill, Ramsey, the metaphysician Carnap (not to be confused with the anti-metaphysician Carnap, who is better known), and Quine. (Acceptance Speech for the Howard T. Behrman Award, 11 May 1991, p. 3)

But then he says:

Among my teachers, besides Quine, I think the one who did most to shape me was Donald Williams. When I reached graduate school a fellow student (now my colleague here) soon told me what was what: I had nothing to learn from doddering Donald, but I would flunk the metaphysics prelim if I didn't waste my time on his out-of-date course. Well, I didn't take the course, I did flunk the prelim, and I flunked it again the next year. All my own silly fault: the trouble, both years, was that I spent three quarters of my time on one quarter of the exam. But I did think it might be prudent to take Williams's course. It was fascinating in its own strange way, but it didn't much connect with any other philosophy I knew. So I went on more or less as before. Twenty years later I looked at my old lecture notes. And there I found all the same questions that had gradually come to the center of my attention since. What's more, I was thinking about them in very much the terms Williams had taught me. What's more, his own position on them looked to be one of the front runners, at the very least. (Acceptance Speech for the Howard T. Behrman Award, 11 May 1991, p. 4)

Lewis's biographical remark suggests that Williams's influence on him was subconscious or unconscious, as if he wasn't aware of what Williams taught him or of Williams's work until the 1980s. But this is, if anything, a partial explanation of what is going on here since it is not the case that Lewis only subconsciously or unconsciously adopted or worked within the spirit of Williams's general metaphysics. I have shown clear instances of Lewis from the 1960s and early 1970s consciously reading, studying, and interacting with Williams as well as mentioning to others that he was sympathetic toward Williams's project.

Lewis is right to note that Williams's focus in metaphysics was outdated. Williams thought philosophers like C. J. Ducasse and Santayana ought to be studied and recognized at a time when these figures were almost never read and/or no one had the patience for grand cosmological visions of reality. To illustrate, Lewis writes to Paul Fitzgerald: 'Donald Williams says the token-reflexive analysis of "actual" occurs in E. B. Holt; I couldn't find it there, but couldn't stand to search for very long. It is in [Arthur] Prior (Theoria XXXIV, 3 (1968), p. 191)' (Letter to Paul Fitzgerald, 30 June 1969, p. 2).

In his discussion of the indexical account of actuality with Lewis, we can see Williams, even as late as the 1960s, looking back to the metaphysics of the early twentieth century. Now the indexical account of 'actual' could well be in or extracted from Holt's metaphysics. But even so, that's not where Lewis got the idea. This pattern probably occurred in other places. But it does not undermine the fact that Williams was exploring the same problems as contemporary metaphysicians. To be fair, Williams did take Goodman's work seriously and assigned certain articles by Quine in his seminars. It is just that Williams had one foot in the past that made him appear out of touch with those around him. Williams's attitude in the 1960s seems to reflect this situation. In his comments on Lewis's PHIL157 term paper he ends with this question: 
'Can it be that my apprehensiveness is merely that of the idle metaphysical sportsman who resents modernized methods which threaten to deplete the game supply?' (Comments on David Lewis's 'How to Establish the Identity Theory', 1 May 1965, p. 3).

Even so, Williams continued to react to current metaphysics late in his life. In his Notre Dame lecture, 'The Bugbear of Fate', Williams rejects Lewis's modal realism as found in Lewis's Counterfactuals (1973) on the grounds that possible worlds do not provide a plausible explanation of counterfactuals, unrestricted combinations of possible worlds lead to set-theoretic-like paradoxes, and modal realism provides no motivation not to realize evil in this world (Lecture 2, pages marked '206-9'; DCW Papers, HUG(FP) 53.45, box 8, folder: 'Fate Notre Dame Lecture 2', HUA). All of these objections were later repeated in the literature by others, and Lewis replied to them in $\mathrm{On}$ the Plurality of Worlds (see Lewis 1986b: ch. 2). Lewis actually quotes Williams's 1974 Notre Dame lectures when discussing the objection that modal realism makes us indifferent to the evils in our world (Lewis 1986b: 123, n. 6). To Lewis's credit he saw the importance of Williams's work and partly as a result Williams's legacy lives on.

The history of analytic metaphysics exhibits far more continuity of genuine metaphysics than is officially acknowledged. Williams held the metaphysics flag high during the height of positivism and linguisticism in the middle of the twentieth century due to his belief that metaphysics was a legitimate enterprise, a belief he inherited from the previous generation of metaphysicians. Given that he was a profound influence on the formation of some of Lewis's metaphysical views and influenced other major philosophers of the latter half of the twentieth century, we can rightfully conclude that Williams played a vital role in the development and revival of metaphysics in the late twentieth century.

ACKNOwLEDGements: Thanks to Helen Beebee, Keith Campbell, Peter Forrest, Katherine Hawley, John Heil, Fraser Macbride, Kris McDaniel, Hugh Mellor, Michaelis Michael, Daniel Nolan, and Jonathan Schaffer for comments and discussion. I am grateful to Harvard University Archives for permission to access material from the Donald Cary Williams Papers and to David C. Williams for permission to publish material by Williams. I further thank Steffi Lewis for permission to cite letters and unpublished material by David Lewis. And finally I thank the John Rylands Research Institute for research support and the British Academy for a Newton International Fellowship that facilitated some of this research.

\section{References}

Adams, Robert Merrihew. (1974) 'Theories of Actuality'. Noûs, 8(3), 211-31.

Alexander, Samuel. (1920) Space, Time, and Deity: The Gifford Lectures at Glasgow 19161918. London: Macmillan.

Armstrong, D. M. (1983) What is a Law of Nature? Cambridge: Cambridge University Press. -. (1993) 'Reply to Forrest'. In J. Bacon, K. Campbell, and L. Reinhardt (eds.), Ontology, Causality and Mind (Cambridge: Cambridge University Press), pp. 65-72.

Brandt, Richard B. (1957) 'The Languages of Realism and Nominalism'. Philosophy and Phenomenological Research, 17(4), 516-35.

Broad, C. D. (1933) Examination of McTaggart's Philosophy. Vol. 1. Cambridge: Cambridge University Press.

Campbell, Keith. (1990) Abstract Particulars. Oxford: Blackwell. 
Glock, Hans-Johann. (2008) What is Analytic Philosophy? Cambridge: Cambridge University Press.

Goodman, Nelson. (1951) The Structure of Appearance. Cambridge, MA: Harvard University Press.

Heil, John. (2012) The Universe As We Find It. Oxford: Clarendon Press.

Holt, Edwin B., et al. (1912) The New Realism: Cooperative Studies in Philosophy. New York: Macmillan.

Lewis, David. (1966) 'An Argument for the Identity Theory'. Journal of Philosophy, 63(1), $17-25$.

-. (1973) Counterfactuals. Cambridge: Harvard University Press.

- (1976) 'The Paradoxes of Time Travel'. American Philosophical Quarterly, 13(2), 145-52.

- (1983a) 'New Work for a Theory of Universals'. Australasian Journal of Philosophy, 61(4), 343-77.

-. (1983b) Philosophical Papers. Vol. 1. New York: Oxford University Press.

-. (1986a) 'Against Structural Universals'. Australasian Journal of Philosophy, 64(1), 25-46.

-. (1986b) On the Plurality of Worlds. Oxford: Basil Blackwell.

-. (1986c) Philosophical Papers. Vol. 2. Oxford: Oxford University Press.

—. (1990) 'Noneism or Allism?'. Mind, 99(393), 23-31.

-. (1991) Parts of Classes. Cambridge, MA: B. Blackwell.

-. (1992) 'Armstrong on Combinatorial Possibility'. Australasian Journal of Philosophy, $70(2), 211-24$.

—. (1994) 'Humean Supervenience Debugged'. Mind, 103(412), 473-90.

—. (1998) 'A World of Truthmakers?'. Times Literary Supplement, 4950, 30-33.

-. (2001) 'Truthmaking and Difference-Making'. Nô̂s, 35(4), 602-15.

Macbride, Fraser. (2014) 'How Hochberg Helped Us Take the Ontological Turn'. Dialectica, 68(2), 163-69.

Maurin, Anna-Sofin. (2002) If Tropes. Dordrecht: Kluwer.

Miller, Kristie. (2005) 'Blocking the Path from Vagueness to Four Dimensionalism'. Ratio, 18(3), 317-31.

Nolan, Daniel. (2007) 'Contemporary Metaphysicians and Their Traditions'. Philosophical Topics, 35(1/2), 1-18.

Putnam, Hilary. (1962) 'It Ain't Necessarily So'. Journal of Philosophy, 59(22), 658-71.

Quine, W. V. (1960) Word and Object. Cambridge, MA: MIT Press.

Schneider, Christina. (2002) 'Relational Tropes: A Holistic Definition'. Metaphysica, 3(2), 97112.

Soames, Scott. (2003) Philosophical Analysis in the Twentieth Century. Princeton: Princeton University Press.

Strawson, P. F. (1959) Individuals: An Essay in Descriptive Metaphysics. London: Methuen. Taylor, Richard. (1963[1992]) Metaphysics Fourth Edition. Englewood Cliffs, NJ: Prentice Hall.

Trettin, Kathe. (2000) 'Tropes and Things'. In J. Faye, U. Scheffler, and M. Urchs (eds.), Things, Facts and Events (Amsterdam: Rodopi), pp. 279-303.

Ushenko, A. P. (1953) 'The Principles of Causality'. Journal of Philosophy, 50(4), 85-101.

Williams, Donald C. (1930) 'The Definition of Yellow and Good'. Journal of Philosophy, 27(19), 515-27.

-. (1931) 'The Nature of Universals and of Abstractions'. The Monist, 41(4), 583-93.

-. (1934a) 'The Argument for Realism'. The Monist, 44(2), 186-209.

-. (1934b) 'Truth, Error and the Location of the Datum'. Journal of Philosophy, 31(16), 428-38.

-. (1937/1938) 'The Realistic Interpretation of Scientific Sentences'. Erkenntis, 7(1), 169-78.

-. (1938) 'The Nature and Variety of the A Priori'. Analysis, 5(6), 85-94.

-. (1944) 'Naturalism and the Nature of Things'. Philosophical Review, 53(5), 417-43.

-. (1946) 'Scientific Evidence and Action Patterns: Rejoinder to Professor Black'. Philosophical Review, 55(5), 580-86. 
-. (1947) The Ground of Induction. Cambridge, MA: Harvard University Press.

-. (1951a) 'The Myth of Passage'. Journal of Philosophy, 48(15), 457-71.

-. (1951b) 'The Sea Fight Tomorrow'. In P. Henle, H. M. Kallen, and S. K. Langer (eds.), Structure, Method and Meaning (New York: Liberal Arts Press), pp. 282-306.

-. (1953a) 'On the Elements of Being: I'. Review of Metaphysics, 7(1), 3-18.

-. (1953b) 'On the Elements of Being: II'. Review of Metaphysics, 7(2), 171-92.

-. (1953c) 'Remarks on Causation and Compulsion'. Journal of Philosophy, 50(4), 120-24.

- (1956) 'The Myth of Passage'. In S. Hook (ed.), American Philosophers at Work: The

Philosophic Scene in the United States (New York: Criterion Books), pp. 315-31.

-. (1959a) 'Mind as a Matter of Fact'. Review of Metaphysics, 13(2), 203-25.

-. (1959b) 'Philosophy and Psychoanalysis'. In S. Hook (ed.), Psychoanalysis, Scientific

Method, and Philosophy (New York: New York University Press), pp. 157-79.

—. (1959[1986]) 'Universals and Existents'. Australasian Journal of Philosophy, 64(1), 1-14.

-. (1963) 'Necessary Facts'. Review of Metaphysics, 16(4), 601-26.

-. (1966a) 'The Nature of Time'. Unpublished, Harvard University Archives, pp. 1-40.

-. (1966b) Principles of Empirical Realism: Philosophical Essays. Springfield, IL: Charles C. Thomas. 